\title{
Trombocitopenia Severa Induzida Por Piperacilina/Tazobactam: A Propósito de Um Caso Clínico
}

\section{Severe Thrombocytopenia Caused by Piperacillin/Tazobactam: A Case Report}

Sara Montezinho1*, Miguel Oliveira², Manuela Alves ${ }^{3}$

*Autor Correspondente/Corresponding Author: Sara Montezinho [saramontezinho@gmail.com]

\section{RESUMO}

A trombocitopenia é um reconhecido efeito secundário a vários fármacos, alimentos, bebidas e produtos de ervanárias. A piperacillina/tazobactam é uma combinação betalactâmico/inibidor da betalactamase de amplo espectro anti-bacteriano, associada a vários efeitos adversos a nível hematológico, sendo o mais frequentemente reportado a neutropenia reversível, mas a anemia hemolítica Coombs positiva e a trombocitopenia também são descritas. Reporta-se um caso clínico de um homem, 73 anos, que desenvolveu trombocitopenia grave induzida pela exposição a piperacilina/tazobactam, confirmada posteriormente pela reexposição ao fármaco.

PALAVRAS-CHAVE: Combinação Piperacilina e Tazobactam/efeitos adversos; Trombocitopenia/induzida quimicamente

\section{ABSTRACT}

Thrombocytopenia is a recognized side effect of various medications, beverages, foods, and herbal remedies. Piperacillin/tazobactam is a beta-lactam/beta-lactamase inhibitor combination with a broad spectrum of antibacterial activity, associated with hematologic adverse such as reversible neutropenia, but Coombs-positive hemolytic anemia and thrombocytopenia are also reported. We report a case of a 73-year-old male patient with severe piperacillin/tazobactam induced thrombocytopenia later confirmed due to re-exposure to the drug.

KEYWORDS: Piperacillin, Tazobactam Drug Combination/adverse effects; Thrombocytopenia/chemically induced

1. Interna de Formação Específica de Medicina Interna, Centro Hospitalar Entre Douro e Vouga, Santa Maria da Feira, Portugal. 2. Interno de Formação Específica de Imuno-Hemoterapia, Centro Hospitalar Universitário do Porto, Porto, Portugal. 3. Assistente Hospitalar Graduada de Medicina Interna, Centro Hospitalar Entre Douro e Vouga, Santa Maria da Feira, Portugal. 


\section{INTRODUÇÃO}

A trombocitopenia é um reconhecido efeito secundário a vários fármacos, alimentos, bebidas e produtos de ervanárias. ${ }^{1,2}$ Diferentes mecanismos foram já identificados como potenciadores desse efeito. Alguns fármacos, como agentes antineoplásicos e imunossupressores, estão associados a supressão medular, que cursa com pancitopenia e inibição seletiva de megacariócitos, resultando em trombocitopenia isolada. Mais frequentemente, mecanismos imunes levam à aceleração da clearance das plaquetas da circulação., ${ }^{2,3}$ A piperacillina/ tazobactam é uma combinação betalactâmico/inibidor da betalactamase de amplo espectro antibacteriano. $O$ efeito adverso mais frequentemente reportado, a nível hematológico, é a neutropenia reversível, mas a anemia hemolítica coombs positiva e a trombocitopenia também são descritas. ${ }^{4}$

A trombocitopenia, assim como outras reações idiossincráticas, afetam apenas uma minoria dos doentes expostos a este fármaco. Não foram ainda identificados fatores genéticos predisponentes. Até 2018 foram reportados 7 casos de trombocitopenia induzida por exposição a piperacilina/tazobactam. ${ }^{5}$ De forma semelhante ao que acontece com outras penicilinas ou derivados, o mecanismo proposto é uma resposta imuno-mediada, em que o fármaco imputado forma uma ligação covalente com a membrana glicoproteica plaquetária e age como um hapteno, induzindo uma resposta mediada por anticorpos. ${ }^{6}$

\section{CASO CLÍNICO}

Descrevemos um caso de um homem, 73 anos, com antecedentes patológicos de colangiocarcinoma (submetido a colocação prévia de prótese biliar), diabetes mellitus tipo 2, anemia dos estados inflamatórios e insuficiência cardíaca de etiologia isquémica, admitido no Serviço de Cirurgia Geral por icterícia obstrutiva e prurido generalizado.

Desde a admissão foi instituída terapêutica com hidroxizina 25 mg oral, enoxaparina 40 mg subcutânea e esomeprazol $40 \mathrm{mg}$ oral. $\mathrm{O}$ doente manteve também a terapêutica crónica habitual com alopurinol 300 mg, carvedilol $25 \mathrm{mg}$, furosemida $40 \mathrm{mg}$, nitroglicerina transdérmica $10 \mathrm{mg} / 24$ horas, insulina glargina 50 unidades, valsartan $40 \mathrm{mg}$, amlodipina 2,5 mg e oxazepam $15 \mathrm{mg}$.

Ao terceiro dia de internamento foi realizada uma colangiopancreatografia retrógrada endoscópica que revelou obstrução total da prótese biliar. Por essa altura o doen- te iniciou febre sustentada $\left(39^{\circ} \mathrm{C}\right)$ e elevação dos marcadores analíticos inflamatórios, iniciando, empiricamente, antibioterapia de largo espectro com piperacilina 4000 mg-tazobactam 500 mg de 8/8 horas, de acordo com protocolos locais. A contagem total de plaquetas era de 246×10 E 9/L.

Cerca de 48 horas após o início dessa terapêutica, antes da realização de colangiografia transhepática percutânea eletiva para drenagem biliar, foram realizadas novas análises sanguíneas, que revelaram uma contagem de plaquetas inferior a 1×10 E 9/L. O tubo coletor usado continha como anticoagulante ácido etilenodiamino tetra-acético (EDTA). Para se proceder à exclusão de pseudotrombocitopenia, foi realizada nova colheita em tubo de Citrato Thromboexact ${ }^{\circledR}$, que revelou contagem sobreponível e inexistência de agregados plaquetários. Cerca de 19,4\% da amostra era composta por plaquetas imaturas. Do restante hemograma há a ressalvar ainda queda de $2 \mathrm{~g}$ de hemoglobina e a observação do esfregaço sanguíneo revelou moderada anisocitose, poiquilocitose, microesferócitos, policromasia, corpos de $\mathrm{Pa}$ ppenheimer e Howell-Jolly. Do restante estudo levado a cabo consequentemente, apresentava 3,37\% de reticulócitos e tempos de protrombina (TP), tromboplastina parcialmente ativada (TTPa), D-dímeros, fibrinogénio, haptoglobina e bilirrubina indireta normais. A bilirrubina total estava aumentada de acordo com a patologia subjacente, mas semelhante ao valor basal para o doente. Durante este período nenhum sinal/sintoma, como perdas hemáticas, petéquias ou púrpura, foram objetivados. Dado o elevado risco de hemorragia em doente com febre e com suspeita de infeção concomitante, foi administrado 1 pool de concentrado plaquetário. Cerca de 1 hora após a transfusão, a contagem plaquetária era de 4×10 E 9/L.

Por suspeita de trombocitopenia induzida pela exposição à antibioterapia, a mesma foi suspensa, verificando-se normalização da contagem plaquetária: 2 dias depois

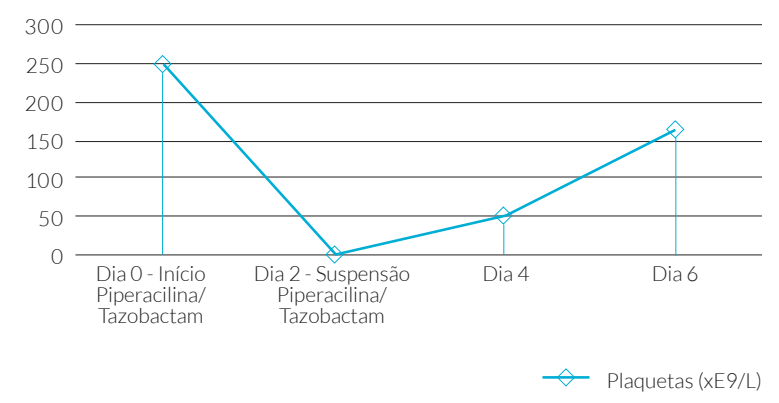

FIGURA 1. Evolução da contagem plaquetária ao longo dos dias desde a introdução da piperacilina/tazobactam e após a sua suspensão. 
a contagem plaquetária era já de 51×10 E 9/L e 4 dias depois era de 162×10 E 9/L (Fig. 1). Após resolução cirúrgica da icterícia obstrutiva que motivou o internamento, o doente teve alta hospitalar.

Cerca de 1 mês após o episódio descrito, o doente é novamente admitido no Serviço de Urgência e posteriormente internado, em contexto de insuficiência cardíaca descompensada por fibrilhação auricular de novo. Durante o internamento desenvolveu febre e elevação dos marcadores de infeção, assumindo-se intercorrência infeciosa nosocomial, iniciando novamente antibioterapia de largo espectro com piperacilina 4000 mg- tazobactam 500 mg 8/8 horas. Cerca de 24 horas após, o hemograma revelou trombocitopenia grave (2×10 E 9/L). 0 esfregaço de sangue periférico demonstrou as mesmas alterações identificadas no primeiro episódio, foi excluída pseudotrombocitopenia, e os restantes resultados documentaram um normal TP, TTPa, D-dímeros, fibrinogénio, haptoglobina e bilirrubina. Clinicamente não houve qualquer manifestação da trombocitopenia. Após revisão do processo clínico do doente e associação dos dois episódios, o antibiótico foi imediatamente suspenso. Três dias depois a contagem de plaquetas era já de 124×10 E 9/L. Neste episódio um alerta eletrónico foi gerado, perpetuando a contraindicação deste fármaco no doente.

\section{DISCUSSÃO}

A associação piperacilina e tazobactam é frequentemente usada nas infeções intra-abdominais e infeções respiratórias nosocomiais. No caso apresentado, os resultados laboratoriais demonstraram que a trombocitopenia surgiu de forma abrupta e severa após a exposição ao fármaco. Este antibiótico parece ter uma farmacocinética pouco linear e a sua clearance é influenciada por vários fatores, incluindo a idade e a função renal. A semivida plasmática da piperacilina/tazobactam varia de 1 a 2 horas, e este facto poderá explicar a rápida resolução da trombocitopenia após suspensão do fármaco. 7,8 De acordo com o historial médico do doente, este nunca havia sido exposto a este fármaco anteriormente, havendo já história de administração de amoxicilina e ácido clavulânico, sem haver evidência de reações semelhantes.

Neste caso, foram administrados outros fármacos de novo, como hidroxizina, esomeprazol e enoxaparina. No que respeita aos dois primeiros fármacos citados, não há referência a trombocitopenia induzida pelos mesmos na literatura, pelo que não foram equacionados como potenciais responsáveis. Quanto à enoxaparina, esta pode induzir trombocitopenia induzida por heparina, no entanto, não costuma estar associada a quedas tão abruptas da contagem plaquetária e, por outro lado, a pontuação de 1 ponto no score 4T, torna esta hipótese pouco provável. ${ }^{9}$ A piperacilina/tazobactam foi o último fármaco iniciado antes da trombocitopenia ser documentada e verificou-se normalização da contagem plaquetária após a sua suspensão.

A trombocitopenia é uma complicação rara e grave da terapêutica com piperacilina e tazobactam. Apesar de ser já reconhecido que o mecanismo básico subjacente é uma resposta imune ao fármaco, os mecanismos específicos envolvidos ainda não são completamente conhecidos, acreditando-se que estejam na dependência de respostas mediadas por anticorpos. ${ }^{10}$

\section{RESPONSABILIDADES ÉTICAS}

CONFLITOS DE INTERESSE: Os autores declaram a inexistência de conflitos de interesse na realização do presente trabalho.

FONTES DE FINANCIAMENTO: Não existiram fontes externas de financiamento para a realização deste artigo.

CONFIDENCIALIDADE DOS DADOS: Os autores declaram ter seguido os protocolos da sua instituição acerca da publicação dos dados de doentes.

CONSENTIMENTO: Consentimento do doente para publicação obtido.

PROVENIÊNCIA E REVISÃO POR PARES: Não comissionado; revisão externa por pares.

\section{ETHICAL DISCLOSURES}

CONFLICTS OF INTEREST: The authors have no conflicts of interest to declare.

FINANCING SUPPORT: This work has not received any contribution, grant or scholarship.

CONFIDENTIALITY OF DATA: The authors declare that they have followed the protocols of their work center on the publication of data from patients.

PATIENT CONSENT: Consent for publication was obtained.

PROVENANCE AND PEER REVIEW: Not commissioned; externally peer reviewed.

\section{REFERÊNCIAS}

1. George JN, Aster RH. Drug-induced thrombocytopenia: pathogenesis, evaluation, and management. Hematology Am Soc Hematol Educ Program. 2009;153-8. doi:10.1182/asheducation-2009.1.153. 
2. Aster RH, Curtis BR, McFarland JG, Bougie DW. Drug-induced immune thrombocytopenia: pathogenesis, diagnosis, and management. J Thromb Haemost. 2009;7:911-8. doi:10.1111/j. 1538-7836.2009.03360.x.

3. Aster RH, Bougie DW. Drug-induced immune thrombocytopenia. N Engl J Med. 2007;357:580-7. doi:10.1056/NEJMra066469.

4. Benli A, Şimşek-Yavuz S, Başaran S, Çağatay A, Özsüt H, Eraksoy H. Hematologic Adverse Effects of Prolonged Piperacillin-Tazobactam Use in Adults. Turk J Haematol. 2018;35:290-5. doi:10.4274/tjh.2018.0127.

5. Updated database on drug induced thrombocytopenia, Department of Biostatistics \& Epidemiology, College of Public Health, OUHSC. [acedido 10 set 2020] Disponível em: http:// www. https://ouhsc.edu/platelets/.

6. Visentin GP, Liu CY. Drug-induced thrombocytopenia. Hematol Oncol Clin North Am. 2007;21:685-vi. doi:10.1016/j. hoc.2007.06.005.

7. Kinzig M, Sörgel F, Brismar B, Nord CE. Pharmacokinetics and tissue penetration of tazobactam and piperacillin in patients undergoing colorectal surgery. Antimicrob Agents Chemother. 1992;36:1997-2004. doi:10.1128/aac.36.9.1997.

8. Hayashi Y, Roberts JA, Paterson DL, Lipman J. Pharmacokinetic evaluation of piperacillin-tazobactam. Expert Opin Drug Metab Toxicol. 2010;6:1017-31. doi:10.1517/17425255.201 0.506187

9. Arepally, G. M. Heparin-induced thrombocytopenia. Blood 2017;129: 2864-72. doi: 10.1182/blood-2016-11-709873.

10. Nicasio AM, VanScoy BD, Mendes RE, Castanheira M, Bulik CC, Okusanya OO, et al. Pharmacokinetics-pharmacodynamics of tazobactam in combination with piperacillin in an in vitro infection model. Antimicrob Agents Chemother. 2016;60:2075-80. doi:10.1128/AAC.02747-15. 